\title{
A Stable Cathode-Solid Electrolyte Composite for Long- Cycle-Life, High Voltage Solid-State Sodium-ion Batteries
}

Erik A. Wu', Swastika Banerjee ${ }^{\dagger}$, Hanmei Tang ${ }^{\dagger}$, Peter M. Richardson, Jean-Marie Doux, Ji Qi, Zhuoying Zhu, Antonin Grenier, Yixuan Li, Enyue Zhao, Grayson Deysher, Han Nguyen, Ryan Stephens, Guy Verbist, Karena W. Chapman, Raphaële J. Clément*, Abhik Banerjee*, Ying Shirley Meng*, and Shyue Ping Ong*

\begin{abstract}
Rechargeable solid-state sodium-ion batteries (SSSBs) hold great promise for safer and more energy-dense energy storage. However, the poor electrochemical stability between current sulfidebased solid electrolytes and high-voltage oxide cathodes has limited their long-term cycling performance and practicality. Here, we report the discovery of $\mathrm{Na}_{3-x} \mathrm{Y}_{1-x} \mathrm{Zr}_{x} \mathrm{Cl}_{6}$ (NYZC) as an ion conductor that is both electrochemically stable (up to $3.8 \mathrm{~V} \mathrm{vs.} \mathrm{Na} / \mathrm{Na}^{+}$) and chemically compatible with oxide cathodes. Its high ionic conductivity of $6.6 \times 10^{-5} \mathrm{~S} \mathrm{~cm}^{-1}$ at ambient temperature, several orders of magnitude higher than oxide coatings, is attributed to abundant $\mathrm{Na}$ vacancies and cooperative $\mathrm{MCl}_{6}$ rotation, resulting in an extremely low interfacial impedance. A SSSB comprising a $\mathrm{NaCrO}_{2}+\mathrm{NYZC}$ composite cathode, $\mathrm{Na}_{3} \mathrm{PS}_{4}$ electrolyte, and $\mathrm{Na}-\mathrm{Sn}$ anode exhibits an exceptional first-cycle Coulombic efficiency of $97.1 \%$ at room temperature and can cycle over 1000 cycles with $89.3 \%$ capacity retention at $40^{\circ} \mathrm{C}$. These findings highlight the immense potential of halide ion conductors for SSSB applications.
\end{abstract}

\section{Introduction}

A solid-state architecture for rechargeable sodium-ion batteries has garnered substantial research interest in recent years. ${ }^{1-5}$ By replacing flammable organic liquid electrolytes with solid electrolytes (SEs), solid-state sodium-ion batteries (SSSB) promise not only higher safety, but also potentially enable higher voltage cathodes, metal anodes, and stacking architectures to achieve higher energy densities. In addition, the higher abundance of sodium relative to lithium makes sodium-ion batteries a more cost-effective alternative, especially for large-scale grid storage applications where low operating costs are more strongly emphasized than a high energy density. ${ }^{6}$ However, an ideal SE has to meet a stringent set of requirements, namely high ionic conductivity, 
low electronic conductivity, and electrochemical, chemical, and mechanical compatibility with electrodes. While major breakthroughs have been made in achieving liquid-like ionic conductivities in sulfide SEs, their poor electrochemical and chemical interfacial stability against common electrodes remains a critical bottleneck for practical applications.

Recently, two lithium halide superionic conductors, $\mathrm{Li}_{3} \mathrm{YCl}_{6}$ and $\mathrm{Li}_{3} \mathrm{YBr} 6$, have been reported as promising SEs for solid-state lithium-ion batteries. ${ }^{7}$ Exhibiting reasonable $\mathrm{Li}^{+}$conductivities in the range of $0.5-0.7 \mathrm{mS} \mathrm{cm}^{-1}$, the most interesting feature of these halide SEs is their electrochemical and chemical compatibility with the $4 \mathrm{~V} \mathrm{LiCoO}_{2}$ cathode. As a result, more reports have emerged on similar halides $\left(\mathrm{Li}_{3} \mathrm{InCl}_{6}\right.$ and $\mathrm{Li}_{x} \mathrm{ScCl}_{3+\mathrm{x}}$ ) that also exhibit high $\mathrm{Li}^{+}$diffusivity, compatibility with $\mathrm{LiCoO}_{2}$, and facile processability. ${ }^{8,9,10}$ Interestingly, unlike the fast Li-ion conducting sulfides or oxides, fast $\mathrm{Li}$-ion conduction in these halide frameworks do not require a bcc anion sublattice, allowing a much wider selection of compositions when designing halide SE chemistries. The $\mathrm{Na}$ analogues $\mathrm{Na}_{3} \mathrm{YCl}_{6}$ and $\mathrm{Na}_{3} \mathrm{YBr}_{6}$ have been relatively less studied. Previous studies have reported experimental ionic conductivities for these compounds on the order of $10^{-4}-10^{-6} \mathrm{~S} / \mathrm{cm}$ at $500 \mathrm{~K}$. These materials are therefore expected to have much lower room-temperature ionic conductivities than their lithium counterparts and to be impractical for SE applications. ${ }^{11}$

Here, we report the data-driven development of $\mathrm{Na}_{3-\mathrm{x}} \mathrm{Y}_{1-\mathrm{x}} \mathrm{Zr}_{\mathrm{x}} \mathrm{Cl}_{6}(\mathrm{NYZCx})$ as a new class of sodium SEs exhibiting high ionic conductivities as well as excellent electrochemical and chemical stability

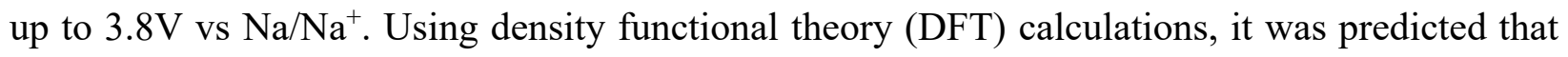
aliovalent doping of $\mathrm{Y}^{3+}$ with $\mathrm{Zr}^{4+}$ would improve the $\mathrm{Na}^{+}$conductivity of $\mathrm{Na}_{3} \mathrm{YCl}_{6}$ by three orders of magnitude, while retaining a wide electrochemical window and good chemical stability. A

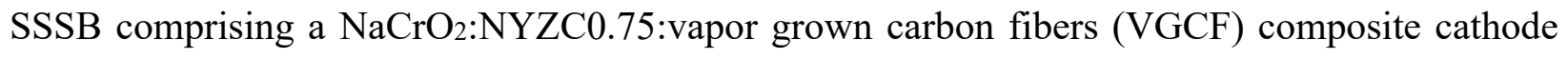
with $\mathrm{Na}_{3} \mathrm{PS}_{4}$ as the SE and a Na-Sn (2:1) anode exhibited an extremely high first cycle Coulombic efficiency (CE) of $97.6 \%$ at room temperature. Even when cycled at $40^{\circ} \mathrm{C}$ and a rate of $1 \mathrm{C}$, the SSSB displayed stable electrochemical performance over 1000 cycles with $89.3 \%$ capacity retention.

\section{Electrochemically Stable and Conductive $\mathrm{Na}_{3-x} \mathrm{Y}_{1-x} \mathrm{Zr}_{x} \mathrm{Cl}_{6}$}

Unlike its lithium counterpart, $\mathrm{Na}_{3} \mathrm{YCl}_{6}$ (NYC) (Fig. 1a, space group: $\mathrm{P} 2{ }_{1} / \mathrm{n}$ ) does not exhibit partial occupancy in the $2 d$ and $4 e \mathrm{Na}$ sites, which may explain its lower ionic conductivity. A 
series of ions $\left(\mathrm{Ti}^{4+}, \mathrm{Zr}^{4+}, \mathrm{Hf}^{4+}\right.$, and $\left.\mathrm{Ta}^{5+}\right)$ were evaluated as potential aliovalent dopants for $\mathrm{Y}^{3+}$ to increase the concentration of defects and thus, the ionic conductivity of $\mathrm{Na}_{3-(\mathrm{z}-3) \times} \mathrm{Y}^{3+}{ }_{1-x} \mathrm{M}^{\mathrm{Z}^{+}}{ }_{x} \mathrm{Cl}_{6}{ }^{2,4,12-}$ ${ }^{14}$ The effect of ionic substitution on the phase stability of NYC is shown in Fig. S1. $\mathrm{Zr}^{4+}$ is predicted to exhibit the lowest dopant formation energies and is also low-cost. Furthermore, the enthalpies of mixing of the NYC-Na2 $\mathrm{ZrCl}_{6}$ (NZC) pseudo-binary system are low, as shown in Fig. $1 b$.

The electrochemical window of $\mathrm{Na}_{3-x} \mathrm{Y}_{1-x} \mathrm{Zr}_{x} \mathrm{Cl}_{6}$ (NYZCx) was investigated using the grand potential phase diagram approach. ${ }^{15,16}$ Consistent with previous studies on the Li analogues, NYZC $x$ SEs exhibit wide electrochemical windows, with a particularly high oxidation limit of $\sim 3.8 \mathrm{~V}$ vs Na/Na${ }^{+}$(Fig. 1c). This high oxidation limit is maintained regardless of $\mathrm{Zr}$ content. However, the reduction limit narrows, from $0.6 \mathrm{~V}$ for NYC to $1.5 \mathrm{~V}$ for NYZC, due to the higher thermodynamic reduction potential of $\mathrm{Zr}^{4+}$ compared to $\mathrm{Y}^{3+}$. The oxidation limit of $3.8 \mathrm{~V}$ for NYZC $x$ indicates that it could be compatible with the $\mathrm{NaCrO}_{2}$ cathode, which has an operating voltage window of 2-3.6 V vs Na/ $\mathrm{Na}^{+} \cdot{ }^{17}$ In contrast, sulfide $\mathrm{SEs}$, such as $\mathrm{Na}_{3} \mathrm{PS}_{4}$, have oxidation limits of only $\sim 2.5 \mathrm{~V}$ vs Na/Na+${ }^{+18}$ In addition, the reaction energies of $\mathrm{NYZC} 0.75$ with $\mathrm{NaCrO}_{2}$ and with metallic Na were found to be less negative than for NPS (Table S2).

The end-members NYC and NZC exhibit a closed-pack arrangement of $\left[\mathrm{YCl}_{6}\right]^{3-}$ and $\left[\mathrm{ZrCl}_{6}\right]^{2-}$ polyanions, respectively. With increasing $x$ in $\operatorname{NYZCx}$, the unit cell volume increases, which results in a widening of the $\mathrm{Na}^{+}$diffusion channels, as shown in Fig. S2. NVT ab initio molecular dynamics (AIMD) simulations were carried out at 600-1000 K for NYZC $x$ for $x=0,0.375,0.5$, and 0.75. For NYC, AIMD simulations indicate no diffusion of $\mathrm{Na}^{+}$ions even at elevated temperatures (Table S1), consistent with its poor ionic conductivity. With $\mathrm{Zr}^{4+}$ doping, $\mathrm{Na}^{+}$ diffusivity increases substantially (Fig. 1d).

Due to the high cost of $a b$ initio methods, NVT AIMD simulations were limited to small supercells and temperatures above $500 \mathrm{~K}$ to ensure sufficient diffusion statistics. To probe the diffusivity at lower temperatures, a highly accurate ML-IAP based on the moment tensor potential formalism was developed using snapshots extracted from the AIMD trajectories as well as ground state and strained structures of NYC, NZC and the highest conductivity NYZC0.75 (see Methods section for details). ${ }^{19-22}$ As shown in Fig. 1d, NVT MD simulations of NYZC0.75 carried out using this 
ML-IAP reproduces the AIMD diffusivities to good accuracy at $600-1000 \mathrm{~K}$. The validated MLIAP was then applied in NpT MD simulations of NYZC0.75 using a much larger cell (592 atoms) over much longer time scales (up to $10 \mathrm{~ns}$ ) at 350 to $650 \mathrm{~K}$. Interestingly, the non-Arrhenius behavior is observed, with a transition between two linear regimes at around 500-550 K. Similar shifts in diffusion characteristics have been previously observed experimentally in NYC and other superionic conductors. ${ }^{11,23}$ The activation barrier for diffusion in the low temperature regime is predicted to be $594 \mathrm{meV}$, and the room temperature $\mathrm{Na}^{+}$conductivity is predicted to be $1.4 \times 10^{-5}$ $\mathrm{S} \mathrm{cm}^{-1}$, which is two orders of magnitude higher than NYC.

a)

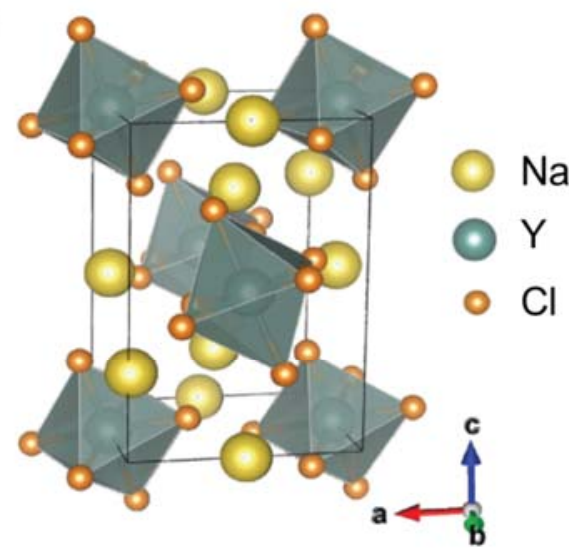

c)

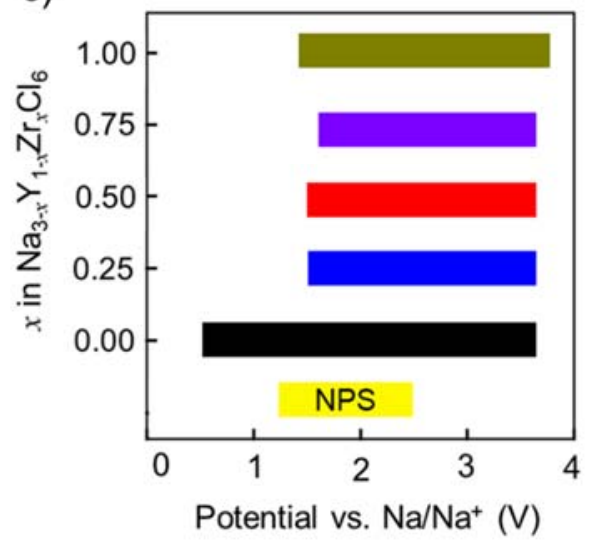

b)

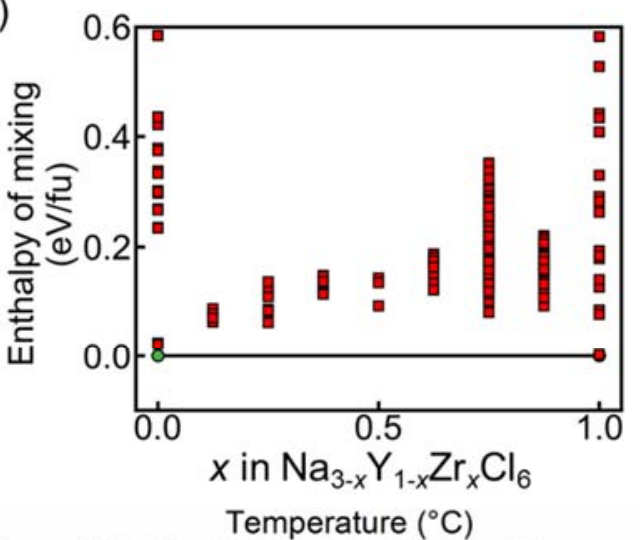

d)

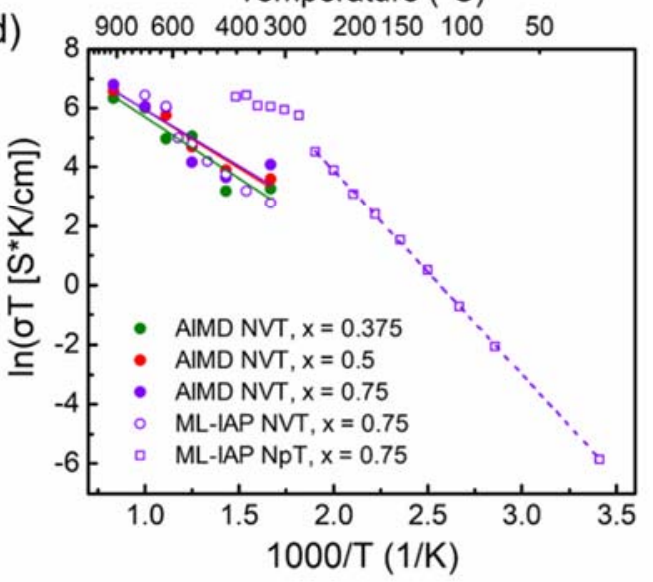

Fig. 1 | Effect of $\mathbf{Z r}$ dopants on properties of $\mathrm{Na}_{3} \mathbf{Y C l}_{\mathbf{6}}$. a, Crystal structure of $\mathrm{Na}_{3} \mathrm{YCl}_{6}$. b, Stability of $\mathrm{Na}_{3-\mathrm{x}} \mathrm{Y}_{1-\mathrm{x}} \mathrm{Zr}_{\mathrm{x}} \mathrm{Cl}_{6}$ after incorporating $\mathrm{Zr}^{4+}$ into $\mathrm{Na}_{3} \mathrm{YCl}_{6}$. Each square marker indicates a symmetrically distinct ordering of $\mathrm{Na}$ and $\mathrm{Y} / \mathrm{Zr}$. c, Electrochemical stability window of $\mathrm{Na}_{3-\mathrm{x}} \mathrm{Y}_{1-\mathrm{x}} \mathrm{Zr}_{\mathrm{x}} \mathrm{Cl}_{6}(0 \leq \mathrm{x} \leq 1)$, with the window of $\mathrm{Na}_{3} \mathrm{PS}_{4}$ (NPS) as a reference. d, Arrhenius plot for $\mathrm{Na}_{3-\mathrm{x}} \mathrm{Y}_{1-\mathrm{x}} \mathrm{Zr}_{\mathrm{x}} \mathrm{Cl}_{6}$ from AIMD 
simulations (at $x=0.375,0.5$, and 0.75; solid lines and markers) and ML-IAP MD simulations (at $x=$ 0.75 ; dashed lines and open markers). AIMD simulations were carried out at $\mathrm{T}=600-1000 \mathrm{~K}$ with an 100 $\mathrm{K}$ interval, using a supercell of 150 atoms for up to $200 \mathrm{ps}$, while the ML-IAP MD simulations were carried out at $\mathrm{T}=350 \mathrm{~K}-650 \mathrm{~K}$ using a supercell of 592 atoms for up to $10 \mathrm{~ns}$.

$\mathrm{NYZC} x$ compounds were experimentally synthesized using stoichiometric amounts of $\mathrm{NaCl}, \mathrm{YCl}_{3}$, and $\mathrm{ZrCl}_{4}$ (see Methods). The parent compound NYC was first synthesized (detailed in Supplementary Note 1) and its XRD pattern and corresponding Rietveld Refinement results are shown in Fig. S3a and Table S3. These results are consistent with previous reports. ${ }^{24}$ The room temperature ionic conductivity of NYC was determined to be $9.5 \times 10^{-8} \mathrm{~S} \mathrm{~cm}^{-1}$ via electrochemical impedance spectroscopy (EIS) measurements (Fig. S3b).

With Zr doping, the P2 1 /n space group of the parent compound NYC is largely retained (Fig. 2a) up to $x=0.875$, suggesting a solid solution in this compositional range. For $x \geq 0.875$, additional peaks emerge in the $\mathrm{XRD}$ patterns at $2 \theta=9.6^{\circ}$ and $10.5^{\circ}$, indicating the presence of a second phase. This phase was determined to be crystalline NZC, which has not been reported previously. Using DFT calculations (Supplementary Note 2 and Fig. S4a), the lowest energy NZC structure was found to be isostructural with $\mathrm{Na}_{2} \mathrm{TiF}_{6}$ (space group P -3 m 1, structures shown in Fig. S4b). ${ }^{25}$ This structure is consistent with experimental synchrotron XRD $(\lambda=0.1668 \AA)$ and Rietveld refinement results of NZC measured after heat treatment (Fig. S4c and Table S4). Furthermore, XPS measurements (Fig. S5) indicate the presence of both $\mathrm{Zr}-\mathrm{Cl}$ and $\mathrm{Y}-\mathrm{Cl}$ bonds (as seen in the $\mathrm{Cl} 2 \mathrm{p}$ region) and thus structural units in the as-prepared NYZC0.5.

Fig. 2b shows the extracted conductivity values (from the respective Nyquist plots in Fig. S6a), over the entire NYZCx compositional range at $\mathrm{x}=0.125$ increments. The ionic conductivity for $0.375 \leq \mathrm{x}<1$ is in the range of 2.6-6.6 x 10-5 $\mathrm{S} \mathrm{cm}^{-1}$, with NYZC0.75 exhibiting the highest conductivity of $6.6 \times 10^{-5} \mathrm{~S} \mathrm{~cm}^{-1}$ (the equivalent circuit fitting is shown in Fig. S6b). Crystalline $\mathrm{NZC}$ was found to have a much lower room temperature conductivity of $1.4 \times 10^{-7} \mathrm{~S} / \mathrm{cm}$ (Fig. S4d), and its presence in the $x \geq 0.875$ compositions explains the observed reduced conductivity. Since NYZC0.75 exhibited the highest conductivity among the compositions, the activation energy was measured (Fig. 2c) and found to be $663.6 \mathrm{meV}$, in good agreement with the ML-IAP NpT simulations for the low temperature regime. In addition, the electronic conductivity of NYZC0.75 was determined to be $8.89 \times 10^{-9} \mathrm{~S} \mathrm{~cm}^{-1}$ via DC polarization (Fig. S7), i.e., NYZC0.75 is an ionic conductor and an electronic insulator. 
It is important to note that the experimental values of the conductivity are somewhat higher than the ML-IAP values. Experimentally, ball milling can introduce disorder and amorphize the sample, and it was previously shown that the relatively less crystalline $\mathrm{Li}_{3} \mathrm{YCl}_{6}$ was demonstrated to have a significantly higher conductivity than its highly-crystalline counterpart. ${ }^{7}$ In contrast, crystalline NYZC0.75 was modelled in the MD simulations. To investigate further, the local Na environments and structural disorder were probed via NMR.
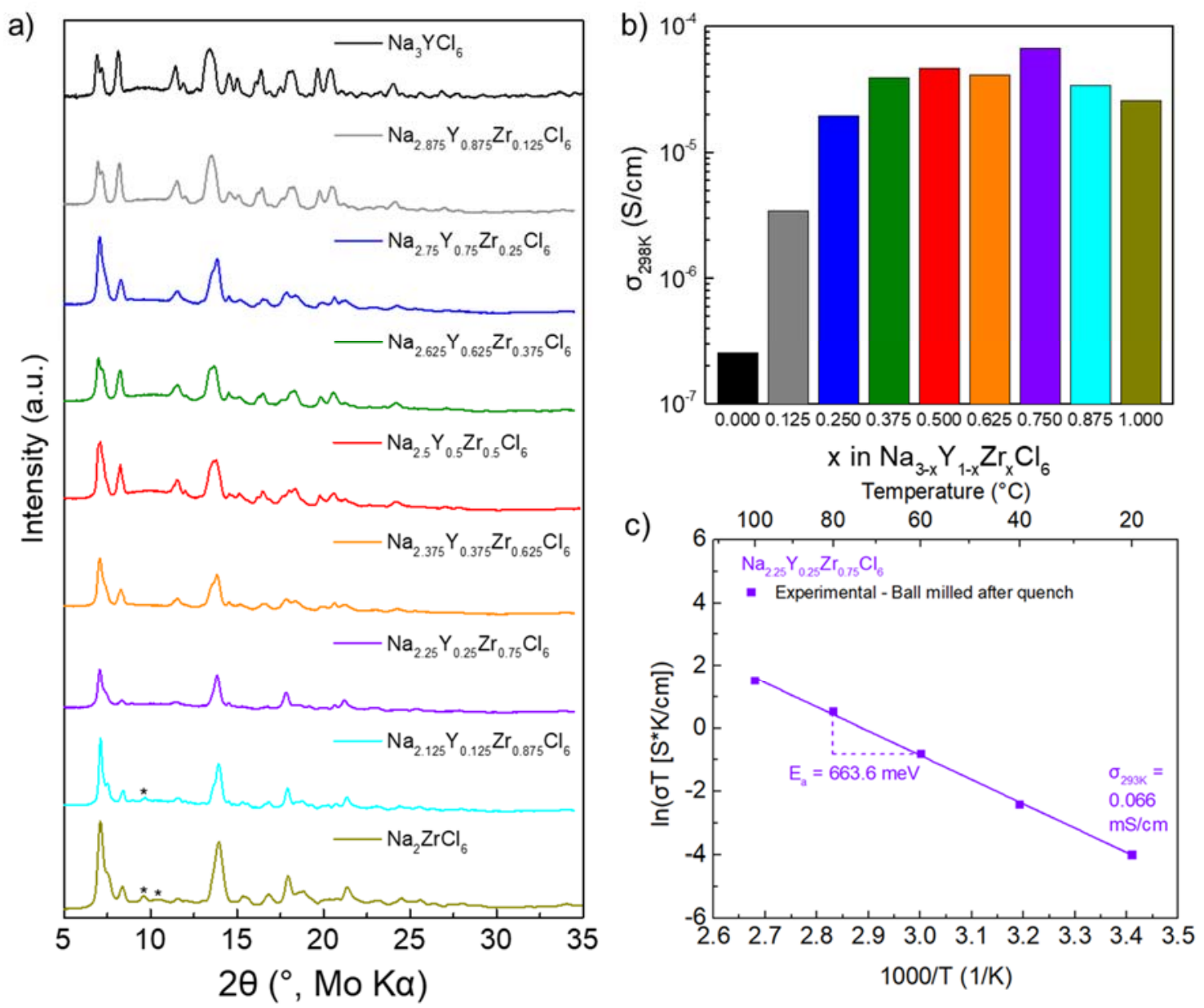

Fig. 2 | Experimental Characterization of $\mathrm{Na}_{3-\mathrm{x}} \mathrm{Y}_{1-\mathrm{x}} \mathrm{Zr}_{\mathbf{x}} \mathbf{C l}_{6}$. a, $\mathrm{XRD}$ of the $\mathrm{Na}_{3-\mathrm{x}} \mathrm{Y}_{1-\mathrm{x}} \mathrm{Zr}_{\mathrm{x}} \mathrm{Cl}_{6}$ compositions, obtained in $\mathrm{x}=0.125$ increments. Asterisks indicate the presence of new peaks. $\mathbf{b}$, The corresponding room temperature conductivity values. c, Arrhenius plot of $\mathrm{Na}_{2.25} \mathrm{Y}_{0.25} \mathrm{Zr}_{0.75} \mathrm{Cl}_{6}$ from experimental measurements. The activation energy (low-temperature regime) and room temperature conductivity values are consistent with the MTP results. 


\section{Local Na environments and disorder}

${ }^{23} \mathrm{Na}$ MAS-NMR spectra obtained on NYZCx $(x=0,0.25,0.5,0.75,1)$ are presented in Fig. 3a. The signal at about $7.2 \mathrm{ppm}$ is attributed to $\mathrm{NaCl}(\mathrm{s})$ present as either an impurity or residual precursor phase in all NYZCx samples. ${ }^{26}$ The $\mathrm{NaCl}$ content obtained from ${ }^{23} \mathrm{Na} \mathrm{NMR}$ signal integration was found to be $16.0 \%, 10.0 \%, 5.9 \%, 6.2 \%$ and $4.0 \%$ for $x=0,0.25,0.5,0.75$ and 1.0, respectively. The decrease in $\mathrm{NaCl}$ impurities with increasing $\mathrm{Zr}$ content is likely due to the concomitant decrease in Na content in NYZCx relative to NYC, which renders the formation of $\mathrm{NaCl}$ less favorable.

a)

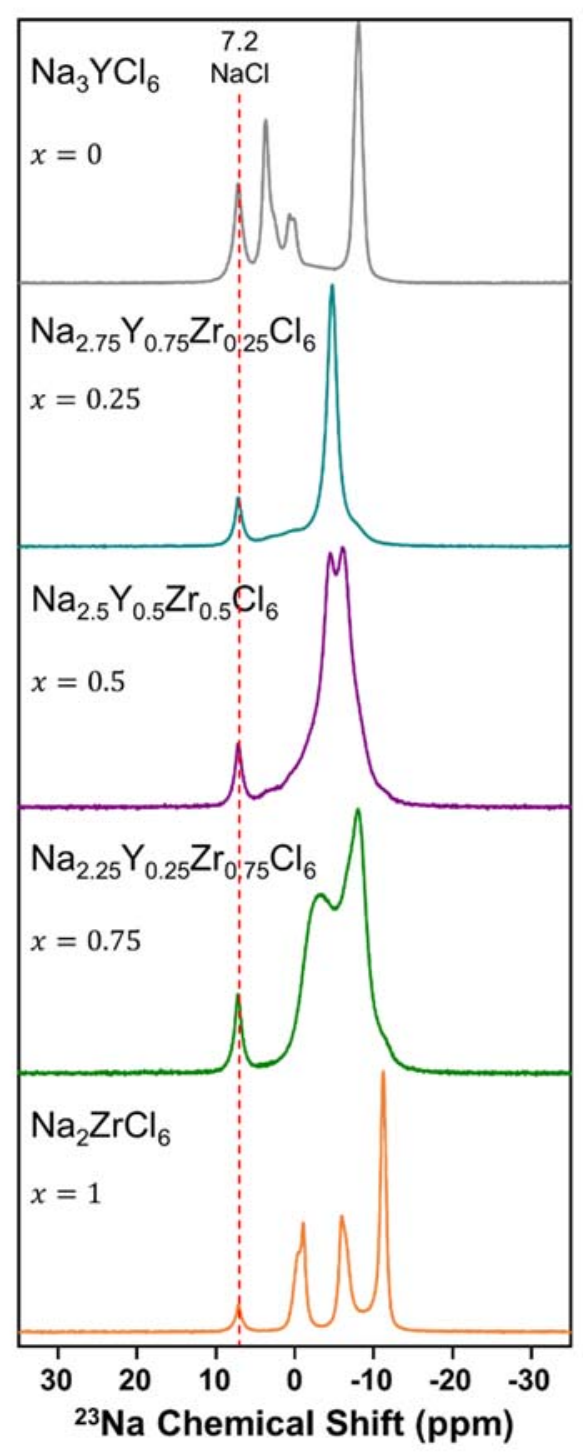

b)

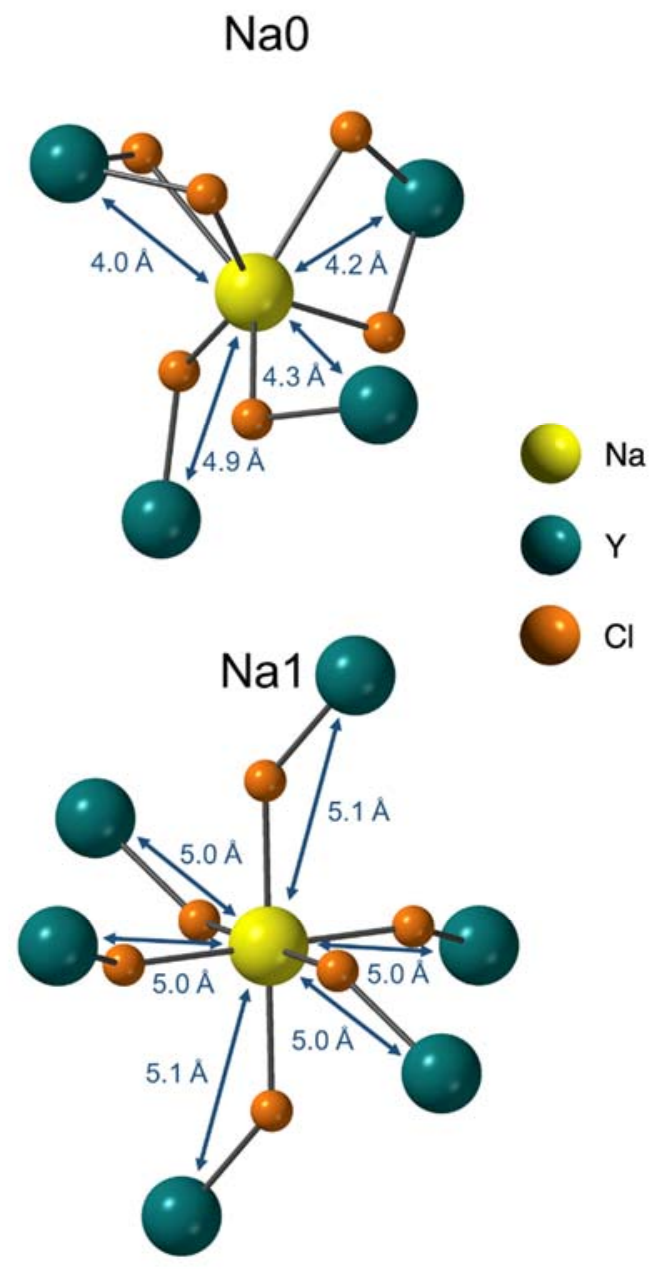


Fig. $3 \mid{ }^{23} \mathrm{Na}$ single-pulse solid-state NMR spectra. a, Spectra collected on $\mathrm{Na}_{3-\mathrm{x}} \mathrm{Y}_{1-\mathrm{x}} \mathrm{Zr}_{\mathrm{x}} \mathrm{Cl}_{6}(\mathrm{x}=0,0.25$, $0.5,0.75$ and 1); the data were acquired at $18.8 \mathrm{~T}$ and at a MAS rate of $12 \mathrm{kHz}$ and at a set temperature of 298 K. b, Schematic of the $\mathrm{Na} 0$ and $\mathrm{Na} 1$ local environments in $\mathrm{Na}_{3} \mathrm{YCl}_{6}$.

While two crystallographically-distinct $\mathrm{Na}$ environments are expected in $\mathrm{Na}_{3} \mathrm{YCl}_{6}$ (as shown in Fig. 3b), the spectrum obtained on this compound (top spectrum in Fig. 3) exhibits at least five distinct resonances besides the $\mathrm{NaCl}$ impurity signal at about $7.2 \mathrm{ppm}$, which suggests the presence of local structural disorder and/or non-stoichiometry. We have excluded the possibility of additional impurity phases in the sample, due to the lack of candidate Na-containing impurity phases with ${ }^{23} \mathrm{Na}$ resonant frequencies and signal line-shapes matching those observed in the $\mathrm{Na}_{3} \mathrm{YCl}_{6}$ spectrum. The presence of well-defined peaks suggests the presence of a range of $\mathrm{Na}$ environments with varying numbers of $\mathrm{Cl}$ and $\mathrm{Y}(\mathrm{Na})$ nuclei in their first and second coordination shells, respectively, as in a non-stoichiometric material or a material with some disorder on the cation lattice. We note that a non-stoichiometric solid electrolyte phase will necessarily result from the presence of a separate $\mathrm{NaCl}$ component, unless some $\mathrm{YCl}_{3}$ impurity is also present in the sample. The latter phase is not observed with XRD, but ${ }^{89} \mathrm{Y}$ NMR data are needed to rule out the presence of amorphous $\mathrm{YCl}_{3}$ in the sample. Non-stoichiometry will also lead to a range of bond angles and bond lengths around Na nuclei in the structure, which could partially account for peak broadening in the $\mathrm{Na}_{3} \mathrm{YCl}_{6}$ spectrum. Additional NMR experiments are underway, as well as first principles calculations of NMR parameters, to fully assign the data presented here.

Previous NMR studies on solid $\mathrm{NaYF}_{4}{ }^{27}$ and the $\mathrm{NaF}_{-} \mathrm{YF}_{3}$ molten system ${ }^{28}$ have shown that the ${ }^{23} \mathrm{Na}$ chemical shift becomes more negative as the number of $\mathrm{Y}^{3+}$ ions in the second coordination shell increases. In stoichiometric $\mathrm{Na}_{3} \mathrm{YCl}_{6}$, the $\mathrm{Na} 0$ site shown in Fig. $3 \mathrm{~b}$ has four $\mathrm{YCl}_{6}$ neighboring octahedra, two of which are edge-sharing with the Y nucleus at a distance of 4.0-4.2 from the central $\mathrm{Na}$, and two of which are corner-sharing with Y-Na distances of 4.3 and $4.9 \AA$. In contrast, the Nal site has six corner-sharing $\mathrm{YCl}_{6}$ neighboring octahedra, with Y being 5.0-5.1 away from the central $\mathrm{Na}$. The presence of non-stoichiometry or disorder on the cation lattice will reduce the number of $\mathrm{Y}$ in the vicinity of the central $\mathrm{Na}$ and more strongly affect the chemical shift of $\mathrm{Na} 0$ (fewer $\mathrm{Y}^{3+}$ neighbors that are closer to the central $\mathrm{Na}$ ) compared to that of $\mathrm{Na}$ (larger number of $\mathrm{Y}^{3+}$ neighbors further away from the central $\mathrm{Na}$ ). It will also lead to additional ${ }^{23} \mathrm{Na}$ NMR signals at more positive ppm values. With this in mind, we tentatively assign the most intense 
${ }^{23} \mathrm{Na}$ resonance at $-8.1 \mathrm{ppm}$ to $\mathrm{Na}$ nuclei in locally stoichiometric $\mathrm{Na} 0$ sites, the resonance at 3.6 ppm to locally stoichiometric Nal sites and the lower intensity peaks in-between these two resonances to $\mathrm{Na}$ nuclei in distorted and/or Y-deficient $\mathrm{Na} 0$ and $\mathrm{Na} 1$ sites. This assignment is consistent with the fact that there are twice as many $\mathrm{Na} 0$ sites than $\mathrm{Na} 1$ sites in the structure, such that the most populated $\mathrm{Na}$ local environment is expected to be the locally stoichiometric $\mathrm{Na} 0$ site. Interestingly, while the substitution $\mathrm{Y}$ by $\mathrm{Zr}$ is expected to vastly increase the number of possible $\mathrm{Na}$ local environments, the ${ }^{23} \mathrm{Na}$ NMR spectra collected on the mixed $\mathrm{Y} / \mathrm{Zr}$ samples exhibit either a single major resonance (as for the $x=0.25$ sample) or two dominant signals (as for the $\mathrm{x}=0.5$ and 0.75 samples). In NMR, if two or more environments are in fast chemical exchange on the experimental timescale, their signals coalesce into a single peak at the weighted average of their resonant frequencies. Notably, the exchange rate at which the signals coalesce depends on the chemical shift separation of the individual resonances for the exchanging sites. Hence, the presence of few resonances in the spectra collected on the $x=0.25,0.5$ and 0.75 compounds indicate fast $\mathrm{Na}^{+}$diffusion in these structures, consistent with the ionic conductivity measurements presented earlier. Given that all three compounds exhibit relatively similar $\mathrm{Na}$ diffusion properties, the fact that a single peak is observed in the $x=0.25$ sample while two broader peaks are observed for the $x=0.5$ and 0.75 samples may stem from a smaller distribution of $\mathrm{Na}$ local environments in the former, leading to chemical shifts that are closer together than in the $x=0.5$ and 0.75 compounds. Finally, the spectrum collected on NZC indicates the presence of at least three distinct Na sites in the structure, not including the $\mathrm{NaCl}$ peak at $7.2 \mathrm{ppm}$. Since the ideal NZC structure contains a single Na environment, the three distinct ${ }^{23} \mathrm{Na}$ resonances could indicate non-stoichiometry or local structural disorder. In addition, $\mathrm{Na}^{+}$diffusion in this compound is too slow to lead to coalescence of the ${ }^{23} \mathrm{Na}$ resonances of the exchanging sites.

\section{Mechanism for Enhanced Conductivity}

To probe the origins of the greatly enhanced conductivity in $\mathrm{NYZCX}$, we compared the probability distributions for both $\mathrm{Na}^{+}$and $\mathrm{Cl}^{-}$in $\mathrm{NYC}$ and $\mathrm{NYZC0.75}$ extracted from 100 ps of AIMD trajectory simulations at $600 \mathrm{~K}$. In NYC, the $\mathrm{Na}^{+}$trajectories (Fig. 4a) indicate mostly local $\mathrm{Na}^{+}$ motion with little long-range transport, consistent with the observed low $\mathrm{Na}^{+}$conductivity. In contrast, fast macroscopic $3 \mathrm{D} \mathrm{Na}^{+}$diffusion is observed for NYZC (Fig. 4b). Interestingly, there 
are substantial differences in the trajectories of the anion framework as well. While the $\mathrm{Cl}^{-}$remain relatively static in NYC even at these elevated temperatures (Fig. 4c), substantial $\mathrm{Cl}^{-}$motion, corresponding to $\mathrm{YCl}_{6}^{3-} / \mathrm{ZrCl}_{6}{ }^{2-}$ octahedra rotations, are observed in $\mathrm{NYZC0} 75$ (Fig. 4d). While similar behavior has been observed in lithium superionic conductors containing borohydride anions $\mathrm{B}_{10} \mathrm{H}_{10}{ }^{2-}{ }^{29} \mathrm{~B}_{12} \mathrm{H}_{12}{ }^{2-},{ }^{30}$ and $\mathrm{BH}_{4}{ }^{-31}$ and the sulfides $\beta$-Lis $\mathrm{PS}_{4}$ and $\mathrm{Li}_{3.25} \mathrm{Si}_{0.25} \mathrm{P}_{0.75} \mathrm{~S}_{4}{ }^{32}$, this is the first observed instance of rotational motion of $\mathrm{Cl}^{-}$in a halide single ion conductor. It is important to note that while there is polyanionic rotation, there is no signature for $\mathrm{Zr}(\mathrm{Y})-\mathrm{Cl}$ bond breaking (Fig. S8).

To investigate the effects of octahedral rotations and lattice volume on $\mathrm{Na}^{+}$conductivities, two gedankenexperiments were performed with $\mathrm{NYZC} 0.75$ where the $\mathrm{YCl}_{6}{ }^{3-} / \mathrm{ZrCl}_{6}{ }^{2-}$ octahedra were frozen in their initial positions and the NYZC0.75 lattice was constrained to the lattice volume of $\mathrm{NYC}$. At $800 \mathrm{~K}, \mathrm{NYZC} x$ with frozen $\mathrm{YCl}_{6}{ }^{3-} / \mathrm{ZrCl}_{6}{ }^{2-}$ octahedra does not exhibit significantly higher $\mathrm{Na}^{+}$diffusivity compared to NYC despite the presence of $\mathrm{Na}^{+}$vacancies and an increased unit cell volume (Fig. 4e). Nevertheless, an increased cell volume due to $\mathrm{Zr}^{4+}$ doping is necessary for $\mathrm{YCl}_{6}{ }^{3-}$ $/ \mathrm{ZrCl}_{6}{ }^{2-}$ octahedral rotations to occur; when NYZC0.75 is constrained to have the same unit cell volume as NYC, the magnitude of the octahedral rotations is greatly reduced (Fig. S9), as is ionic conductivity.

Similar analysis was carried out using the trajectories from the ML-IAP NpT MD simulations at $500 \mathrm{~K}$ and $550 \mathrm{~K}$, i.e., below and above the transition point for the two linear regimes in Fig. 1d, respectively. It was found that the $\mathrm{Na}^{+}$diffusion topology changes from being quasi-2D to being $3 \mathrm{D}$ at the transition temperature, accompanied by a sharp increase in the degree of $\mathrm{YCl}_{6}{ }^{3-} / \mathrm{ZCCl}_{6}{ }^{2-}$ octahedra rotation (Fig. S10). We may therefore surmise that the much lower barriers for $\mathrm{Na}^{+}$ diffusion in the high-temperature regime compared to the low-temperature regime is due to the activation of additional rotational modes and diffusion pathways above the transition temperature. These results highlight the cooperative interplay between increased lattice volume ${ }^{33}$ and octahedral rotations in enhancing the long-range $\mathrm{Na}^{+}$conductivity in this framework. 

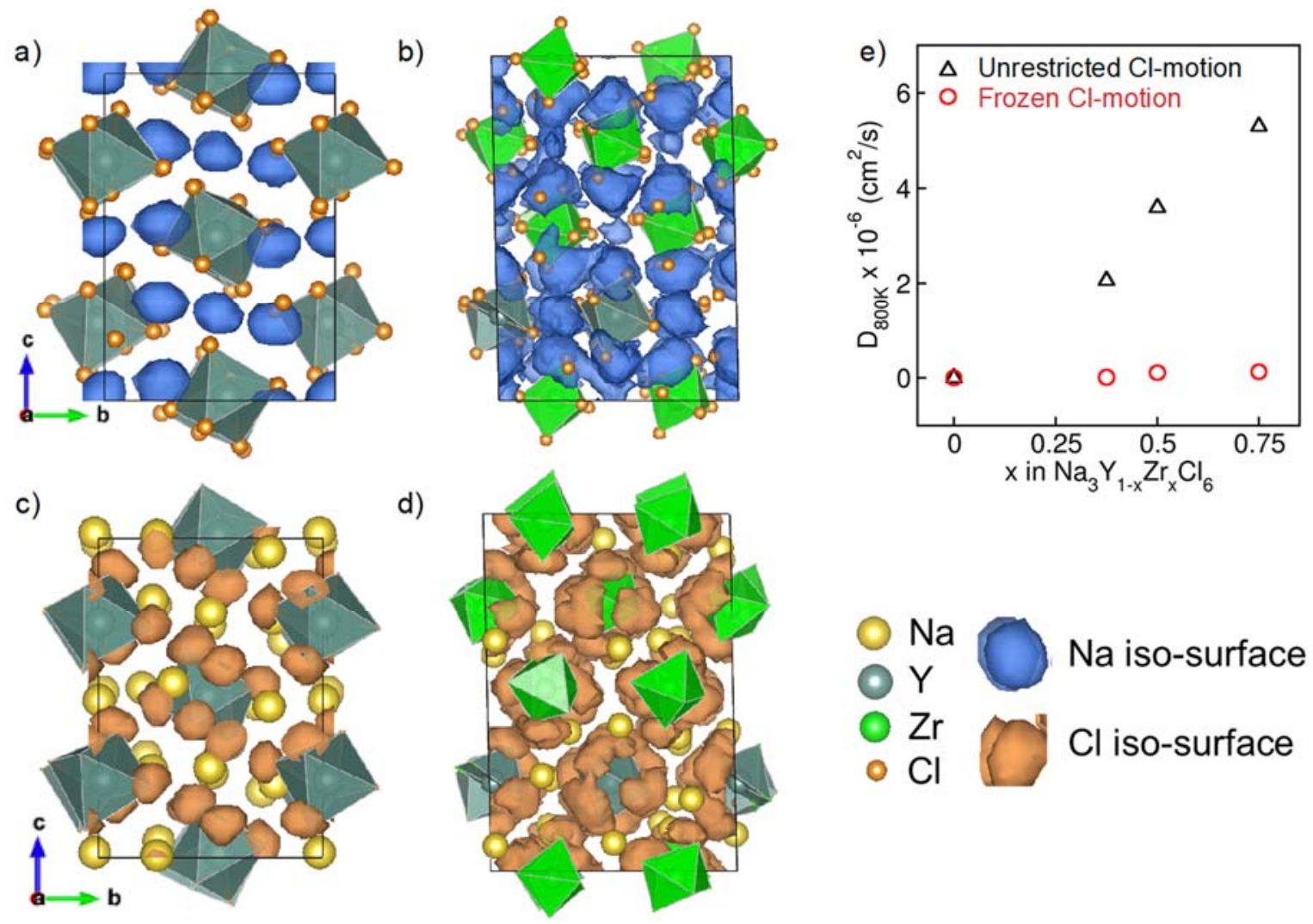

Fig. 4 | Effect of octahedra rotation on $\mathrm{Na}^{+}$diffusivity. Plots of the probability density (isosurface value $=5 \times 10^{-4}$ ) of $\mathbf{a}, \mathrm{Na}^{+}$in $\mathrm{Na}_{3} \mathrm{YCl}_{6}, \mathbf{b}, \mathrm{Na}^{+}$in $\mathrm{Na}_{2.25} \mathrm{Y}_{0.25} \mathrm{Z}_{0.75} \mathrm{Cl}_{6}, \mathbf{c}, \mathrm{Cl}^{-}$in $\mathrm{Na}_{3} \mathrm{YCl}_{6}$ and $\mathbf{d}, \mathrm{Cl}^{-}$in $\mathrm{Na}_{2.25} \mathrm{Y}_{0.25} \mathrm{Z}_{0.75} \mathrm{Cl}_{6}$, over 100 ps of AIMD simulations at $600 \mathrm{~K}$. The motion of $\mathrm{Na}^{+}$and $\mathrm{Cl}^{-}$in $\mathrm{Na}_{3} \mathrm{YCl}_{6}$ are relatively localized, while macroscopic $\mathrm{Na}^{+}$diffusion with $(\mathrm{Zr} / \mathrm{Y}) \mathrm{Cl}_{6}$ octahedral rotation are observed in $\mathrm{Na}_{2.25} \mathrm{Y}_{0.25} \mathrm{Z}_{0.75} \mathrm{Cl}_{6}$. e, $\mathrm{Na}^{+}$diffusivity at $800 \mathrm{~K}\left(\mathrm{D}_{800 \mathrm{~K}}\right.$, in $\left.\mathrm{cm}^{2} / \mathrm{s}\right)$ for varying $\mathrm{Zr}$ content in $\mathrm{Na}_{3-\mathrm{x}} \mathrm{Y}_{1-\mathrm{x}} \mathrm{Zr}_{\mathrm{x}} \mathrm{Cl}_{6}$, compared with a selective dynamics simulation with $\mathrm{Cl}^{-}$ions frozen in space, which shows negligible $\mathrm{Na}^{+}$ diffusivity.

\section{Cathode Composite for Long Cycle-Life Solid-State Sodium Battery}

Given the high cathodic stability and conductivity of NYZC0.75, cells comprising NYZC0.75 in a composite with the $\mathrm{NaCrO}_{2}$ cathode and $\mathrm{Na}_{3} \mathrm{PS}_{4}$ as the SE were constructed; a schematic is shown in Fig. 5a. For comparison, a control cell using Na3PS4 alone, without NYZC0.75, was also constructed (Fig. S11a). At $20^{\circ} \mathrm{C}$ at a rate of C/10 (Fig. 5b-c for NYZC0.75 and Fig. S11b-c for NPS) it is evident that the first cycle Coulombic efficiency (CE) drastically increased in the NYZC0.75 cell (from $71.9 \%$ to $97.6 \%$ ). This observed first cycle CE for the NYZC0.75 cell is the 
highest among those reported for $\mathrm{Na} \mathrm{ASSB}$ that use $\mathrm{NaCrO}_{2}$ as the cathode. ${ }^{5,34-36} \mathrm{We}$ believe that the high cathodic limit of NYZC 0.75 protects the $\mathrm{Na}_{3} \mathrm{PS}_{4} \mathrm{SE}$ from oxidation by $\mathrm{NaCrO}_{2}$, and in turn the $\mathrm{Na}_{3} \mathrm{PS}_{4} \mathrm{SE}$ forms a stable passivating interface with the Na-Sn anode. ${ }^{7}$ This is consistent with results from symmetric cell experiments carried out using either NYZCx or NPS with Na-Sn alloys (Fig. S12).

To study the rate capability of the NYZC 0.75 cell configuration, additional cells were constructed and tested at $\mathrm{C} / 2$ (after the first 5 cycles at $\mathrm{C} / 10$ ) at both $20^{\circ} \mathrm{C}$ and $40^{\circ} \mathrm{C}$ (Figs. $5 \mathrm{~d}$-e and 5f-g, respectively). At $20^{\circ} \mathrm{C}$, there is a noticeable drop in capacity (from 101 to $53.7 \mathrm{mAh} / \mathrm{g}$ ) after switching to a rate of $\mathrm{C} / 2$. This is due to several reasons: one, the NPS layer is relatively thick $(\sim 800 \mu \mathrm{m})$ and the conductivity of NYZC0.75 is in the order of $10^{-5} \mathrm{~S} / \mathrm{cm}$. It is important to note that the cyclical behavior in Fig. 5e is due to temperature variations in the glovebox, as the cell was not inside a temperature-controlled chamber. At $40^{\circ} \mathrm{C}$, where the conductivity of NYZC 0.75 is in the range of $1-2 \times 10^{-4} \mathrm{~S} / \mathrm{cm}$, the drop in capacity is negligible (from 104 to $101 \mathrm{mAh} / \mathrm{g}$ ) when switching to a rate of $\mathrm{C} / 2$. For this particular SSSB, the average $\mathrm{CE}$ is $99.96 \%$, which yields a capacity retention of $88 \%$ after 500 cycles. Furthermore, another NYZC0.75 SSSB was constructed and cycled at $40^{\circ} \mathrm{C}$ and at a rate of $1 \mathrm{C}$ (Figs. 5h-i). This cell can cycle over 1000 cycles with a capacity retention of $89.3 \%$, further highlighting the superior stability of NYZC 0.75 when paired with $\mathrm{NaCrO}_{2}$. To date, this is the highest capacity retention obtained for a SSSB, and Fig. 6 compares cycling performance metrics (gravimetric energy density per active mass, cycle life, capacity retention, rate, and cathode type) across various SSSB reports. ${ }^{5,35,37-50}$

In addition, an NPS control cell was also cycled $40^{\circ} \mathrm{C}$ and C/10 (Fig. S11d-e); the first cycle CE decreased from $71.9 \%$ (at $20^{\circ} \mathrm{C}$ ) to $62.4 \%$, showing that NPS oxidation is exacerbated at $40^{\circ} \mathrm{C}$. This result contrasts with the demonstrated superior electrochemical stability of NYZC0.75 at $40^{\circ} \mathrm{C}$ and high rates.

Furthermore, to investigate the effect of reducing the thickness of NPS, a modified cell design with a stainless steel (current collector) support was fabricated, such that the amount of NPS is reduced by half. Additional details can be found in Supplementary Note 3, and the rate capability test and 
EIS are shown in Fig. S13. Based on these results, thinning the electrolyte layer (or reducing the amount of inactive material) and further optimization of the cell configuration is a promising avenue for future work.

a)
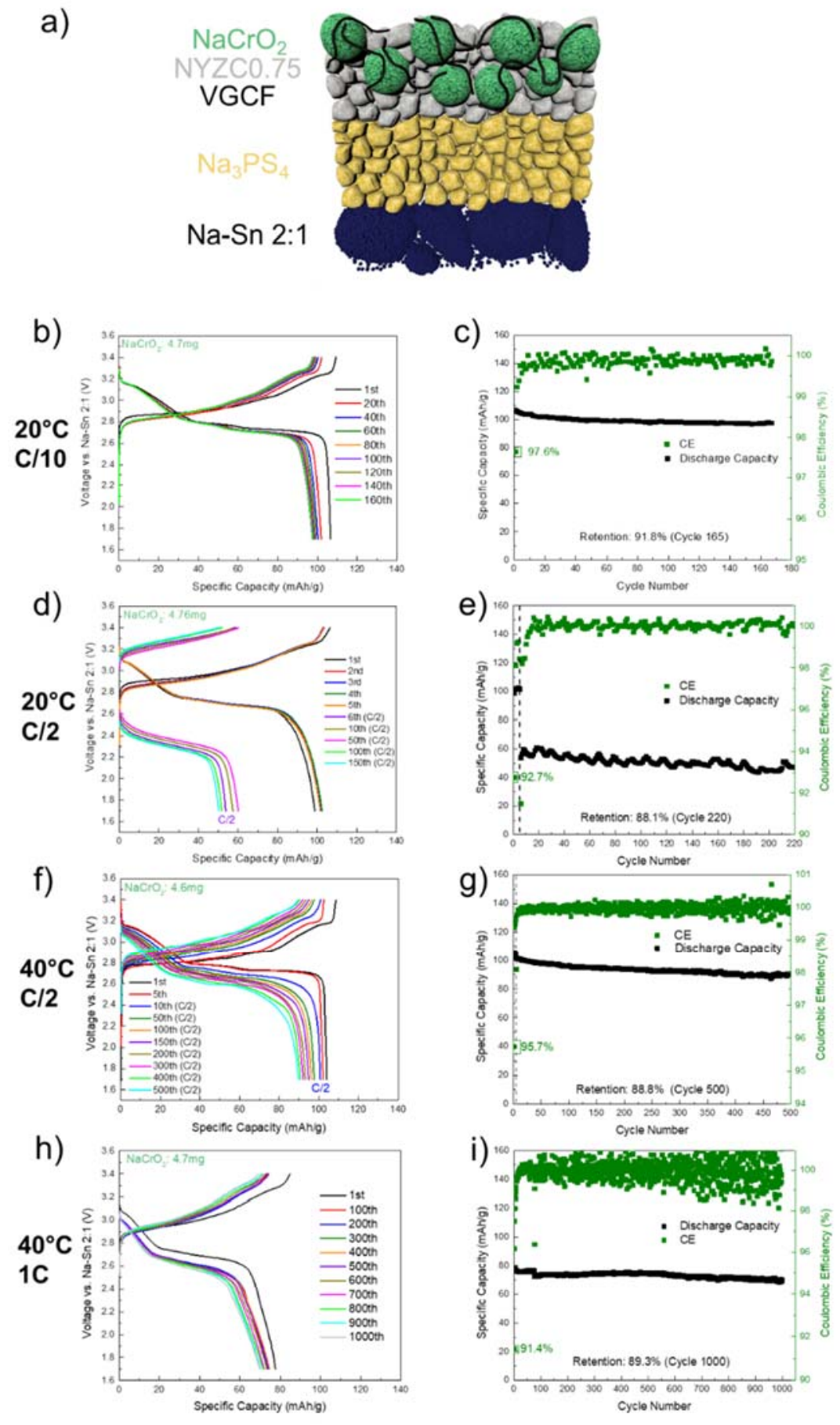
Fig. 5 | Electrochemical performance of the NYZC0.75 SSSBs. a, Cell schematic. Voltage profile and specific capacity as a function of cycle number of this cell configuration, respectively, running at: b-c, $20^{\circ} \mathrm{C}$ and $\mathrm{C} / 10, \mathbf{d}-\mathbf{e}, 20^{\circ} \mathrm{C}$ and $\mathrm{C} / 10$ for the first 5 cycles and subsequent cycling at $\mathrm{C} / 2, \mathbf{f}-\mathbf{g}, 40^{\circ} \mathrm{C}$ and $\mathrm{C} / 10$ for the first 5 cycles and subsequent cycling at $\mathrm{C} / 2$, and $\mathbf{h}-\mathbf{i}, 40^{\circ} \mathrm{C}$ and $1 \mathrm{C}$. In each case, the NYZC0.75 cells exhibit long-term cycling stability, with $89.3 \%$ capacity retention at 1000 cycles for the $40^{\circ} \mathrm{C} 1 \mathrm{C}$ cell.
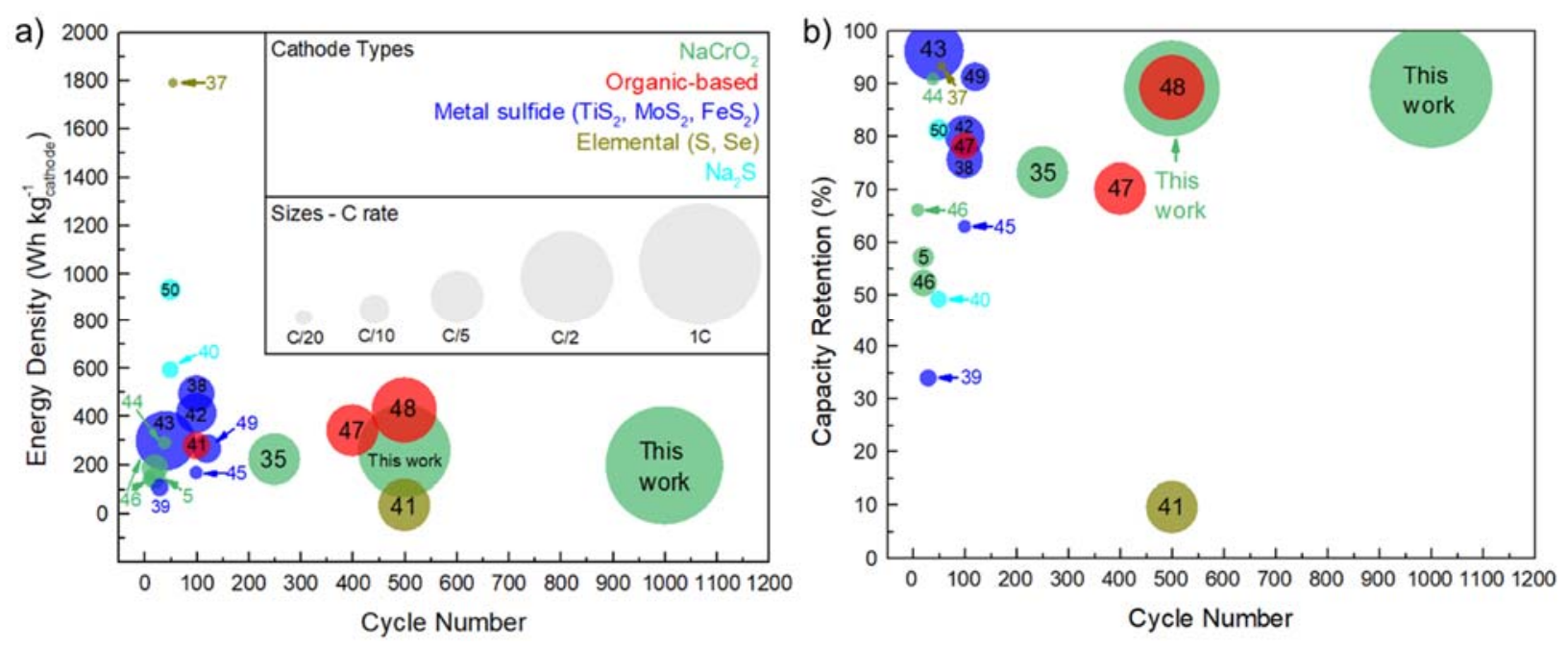

Fig. 6 | Comparison of SSSB Performance Metrics. a, Gravimetric energy density (per mass of active material) plotted as a function of cycle number. b. Capacity retention as a function of cycle number. ${ }^{5,35,37-}$ 50 The cycling performance comparison highlights the compatibility and stability of the $\mathrm{NaCrO}_{2}+$ $\mathrm{Na}_{2.25} \mathrm{Y}_{0.25} \mathrm{Zr}_{0.75} \mathrm{Cl}_{6}+\mathrm{VGCF}$ composite cathode.

To characterize the chemical environments in NPS and NYZC0.75 components after cycling, the SSSBs were disassembled to recover the composite cathodes and XPS measurements were conducted. Fig. S14 compares the S 2p and P 2p binding energy regions of pristine NPS and the cycled NPS-containing composite cathode. Consistent with previous reports, when paired with an oxide cathode, NPS oxidizes to form elemental sulfur, other $\mathrm{P}_{2} \mathrm{~S}_{\mathrm{x}}$ compounds, and possibly compounds containing P-O bonds. ${ }^{18,51,52}$ Fig. S15 shows the Zr 3d and Y 3d bonds of pristine versus cycled NYZC0.75. Even with cells cycled at elevated temperatures or high rates, the $\mathrm{Zr}-\mathrm{Cl}$ and $\mathrm{Y}-\mathrm{Cl}$ bonds are retained in the composite cathode, confirming the electrochemical stability of NYZC0.75 when used with $\mathrm{NaCrO}_{2}$. 
To evaluate the chemical stability, temperature-dependent XRD patterns were collected for 1:1

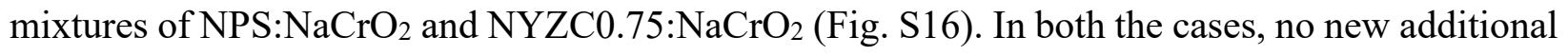
peaks appeared, indicating no chemical reaction, even at temperatures as high as $220^{\circ} \mathrm{C}$. This is in accordance with Table S2, where the reaction energy with $\mathrm{NaCrO}_{2}$ is low for both NPS (-0.18 eV/atom) and NYZC0.75 (-0.14 eV/atom). Thus, the observed superior cycling stability of NYZC0.75 arises from its intrinsic chemical stability in combination with its wide electrochemical window, whereas NPS is electrochemically unstable in presence of high voltage oxide cathode and undergoes oxidative decomposition during charging.

\section{Conclusion}

In this work, we reported on aliovalent substitution in the halide-based ionic crystal $\mathrm{Na}_{3} \mathrm{YCl}_{6}$, which leads to phases with enhanced $\mathrm{Na}^{+}$conduction due to the presence of an interconnected network of $\mathrm{Na}^{+}$diffusion channels (specifically, substituting $\mathrm{Y}^{3+}$ in $\mathrm{Na}_{3} \mathrm{YCl}_{6}$ with $\mathrm{Zr}^{4+}$ to form $\left.\mathrm{Na}_{3-\mathrm{x}} \mathrm{Y}_{1-\mathrm{x}} \mathrm{Zr}_{\mathrm{x}} \mathrm{Cl}_{6}\right) . \mathrm{Zr}^{4+}$ substitution was found to increase the volume of the unit cell, which in turn enables polyanion rotation. The synergy between polyanionic rotation and increase in the effective mobile carrier concentration leads to a significant increase in the $\mathrm{Na}^{+}$diffusivity upon $\mathrm{Zr}$ incorporation, which is absent in the parent $\mathrm{Na}_{3} \mathrm{YCl}_{6}$ compound. This was confirmed experimentally by an increase in the ionic conductivity by two orders of magnitude upon $\mathrm{Zr}$ substitution. Furthermore, the wide oxidative electrochemical window (up to $3.8 \mathrm{~V}$ ) was retained after substitution, which proved to be beneficial when paired with a $\mathrm{NaCrO}_{2}$ cathode in a model SSSB. In this configuration, no electrochemical decomposition was observed, in contrast with a cell comprising $\mathrm{Na}_{3} \mathrm{PS}_{4}$ in the cathode composite, as revealed by XPS. At $40^{\circ} \mathrm{C}$ and a rate of $1 \mathrm{C}$, the cell containing $\mathrm{Na}_{2.25} \mathrm{Y}_{0.25} \mathrm{Zr}_{0.75} \mathrm{Cl}_{6}$ was able to cycle over 1000 cycles with a capacity retention of $89.3 \%$, the highest cycle life for a SSSB to date. Thus, further exploration of halide-based materials, especially in SSSBs, is a worthy area of continued investigation. This methodology of coupling computational and experimental evaluation, verification, and testing of material properties is an effective and necessary strategy toward finding compatible, long-lasting, and highperforming SSSB chemistries. 


\section{Methods}

\section{Structural relaxations and energy calculations}

All density functional theory (DFT) calculations were performed using the projector augmented wave (PAW) approach as implemented in the VASP package. ${ }^{53,54}$ The Perdew-Burke-Ernzerhof (PBE) generalized gradient approximation functional was used. ${ }^{55}$ A plane-wave cut-off of $520 \mathrm{eV}$ was used for DFT relaxations and energy calculations, consistent with the settings used in the Materials Project database. ${ }^{56}$ All input file generation and post-processing analysis were performed using Pymatgen and pymatgen-diffusion packages. ${ }^{57}$

The pre-relaxed structures of $\mathrm{Na}_{3} \mathrm{YCl}_{6}$ (mp-31362) and $\mathrm{Na}_{3} \mathrm{YBr}_{6}$ (mp-29080) were extracted from the Materials Project (MP) database ${ }^{58,59}$. The corresponding $\operatorname{ICSD}^{60}$ ids are $\# 59886$ and \#82355, respectively. Aliovalent substitution on the $\mathrm{Y}^{3+}$ sites with charge compensation by $\mathrm{Na}^{+}$vacancies were performed to generate $\mathrm{Na}_{3-(\mathrm{z}-3) \mathrm{x}} \mathrm{Y}_{1-\mathrm{x}} \mathrm{M}^{\mathrm{z}^{+}}{ }_{\mathrm{x}} \mathrm{Cl}_{6}\left(\mathrm{M}=\mathrm{Ti}^{4+}, \mathrm{Zr}^{4+}, \mathrm{Hf}^{4+}, \mathrm{Ta}^{5+}\right)$ structures. DFT calculations were performed on all symmetrically distinct orderings of $\mathrm{Y} / \mathrm{M}$ and $\mathrm{Na} / \mathrm{vacancies}$ to identify the lowest energy structure. Candidate structures for the hitherto-unreported $\mathrm{Na}_{2} \mathrm{ZrCl}_{6}$ phase were obtained by performing ionic substitutions of all structures in MP database matching the formula of $\mathrm{A}_{2} \mathrm{MX}_{6}$. All candidate structures were fully relaxed using DFT prior to calculating their energies. The computed XRD pattern of the lowest energy candidate was successfully matched to the experimental XRD pattern.

Other than the target phases of interest, the pre-computed energies of all other structures in the Na$\mathrm{Y}-\mathrm{Zr}-\mathrm{Cl}$ phase space were obtained from the Materials Project database and used in the calculation of the energy above hull $\left(E_{\text {hull }}\right)$, electrochemical stability window, and the interfacial reaction products following the methodologies established in prior publications. ${ }^{18,61}$

Topological analysis of the framework chemistries was performed using $\mathrm{Zeo}++$, an open source topological analysis package. ${ }^{62}$ The quantity of interest is the largest included sphere radius along the free sphere path $R_{i n c}$. This gives an estimate of the diffusion channel size which is associated with the ionic conductivity of the material.

\section{Ab initio molecular dynamics}


Non-spin polarized ab initio molecular dynamics (AIMD) simulations were carried out in the NVT ensemble. A plane-wave energy cutoff of $280 \mathrm{eV}$, supercells with the minimum dimension larger than $10 \AA$ and a minimal $\Gamma$-centered $1 \times 1 \times 1 \mathrm{k}$-mesh were used. The time step was set to $2 \mathrm{fs}$. Simulations were carried out at several temperatures between $500 \mathrm{~K}$ and $1200 \mathrm{~K}$ and the corresponding diffusivities were extracted using the Nernst-Einstein relationship from the slope of the plot of the mean square displacement of $\mathrm{Na}$ ions with time.

\section{Machine learning interatomic potential and molecular dynamic simulations}

The moment tensor potential (MTP) for NYZC0.75 was developed using the open-source Materials Machine Learning (maml) Python package. The training data comprises 800 snapshots extracted at 400 fs intervals from AIMD NVT simulations at $600 \mathrm{~K}, 800 \mathrm{~K}, 1000 \mathrm{~K}$, and $1200 \mathrm{~K}$. Static DFT calculations were then performed to obtain accurate energies and forces. A training:test split of 90:10 was used to train the machine learning model. The MTP cutoff radius and the maximum level of basis functions, $l e v_{\max }$ were chosen to be $5.0 \AA$ and 14 , respectively. The mean absolute error (MAE) on the energies and forces were $1 \mathrm{meV}^{-1}$ atom ${ }^{-1}$ and $63.5 \mathrm{meV} \AA^{-1}$, respectively (Fig. S17). NPT MD simulations using the MTP were carried out using LAMMPS. ${ }^{63}$ The simulation time was at a least amount of $10 \mathrm{~ns}$ with a 2 fs time step. A $4 \times 4 \times 4$ supercell of the NYC0.75 with 592 atoms was used.

\section{Experimental Synthesis and Characterization}

\section{Material Synthesis}

All fabrication processes were conducted in an Ar-filled glovebox (mBraun 200B, $\mathrm{H}_{2} \mathrm{O}$ ppm $<0.5$, $\mathrm{O}_{2} \mathrm{ppm}<1$ ), unless otherwise noted.

Stoichiometric amounts of the precursors $\mathrm{NaCl}\left(>99 \%\right.$, Sigma Aldrich), $\mathrm{YCl}_{3},(99.9 \%$, Sigma Aldrich) were hand-mixed in a mortar and pestle for 10 minutes and the powder mixture was placed in a $50 \mathrm{~mL} \mathrm{ZrO}_{2}$ ball mill jar (Retsch Emax) with eleven $10 \mathrm{~mm}$-diameter $\mathrm{Y}_{-} \mathrm{ZrO}_{2}$ milling balls. The mixture was milled for 2 hours at $500 \mathrm{rpm}$. The material was extracted from the jars in the glovebox, pelletized at a pressure of $370 \mathrm{MPa}$ with a $13 \mathrm{~mm}$ pellet die (Carver), loaded into a quartz tube, flame sealed, and heated in a box furnace (Lindberg Blue M) at $500{ }^{\circ} \mathrm{C}$ for 24 hours. 
To homogenize the material, the material was ball milled again after heat treatment using $885 \mathrm{~mm}$ diameter $\mathrm{Y}-\mathrm{ZrO}_{2}$ milling balls for a duration of 4 hours. The material was extracted and stored in the glovebox before further testing.

For the $\mathrm{Zr}$ substituted compounds, the same procedure was conducted with the addition of $\mathrm{ZrCl}_{4}$ (99.99\%, Sigma Aldrich) as a third precursor, and the reagent ratios adjusted according to stoichiometry.

\section{Characterization - XRD}

Powder samples were loaded into $0.5 \mathrm{~mm}$-diameter boron-rich capillary tubes (Charles Supper). The tube opening was capped with clay and wrapped in paraffin film before it was brought outside of the glovebox to be flame-sealed with a butane torch. The samples were measured on a Bruker Kappa goniometer equipped with a Bruker Vantec 500 detector. The sample was placed in the Bragg-Brentano $\theta-\theta$ configuration and the Debye-Scherrer method was used for measurements. $\mathrm{XRD}$ data was collected using $\mathrm{Cu} \mathrm{K} \alpha$ radiation at $45 \mathrm{kV}$ and $50 \mathrm{~mA}$, over a $2 \theta$ range of 5-90 with a step size of $0.01^{\circ}$.

For temperature-dependent capillary $\mathrm{XRD}$, the capillary tubes were heated at a rate of $5^{\circ} \mathrm{C} / \mathrm{min}$ and held at the target temperature for one hour before the XRD measurement was taken.

For Synchrotron XRD, the samples were prepared by loading the powders into polyimide tubes in the glovebox and were subsequently sealed with epoxy. Measurements were carried out at Beamline 28-ID-1 at NSLS-II.

\section{Characterization - Electrochemical}

The powder was pressed at $370 \mathrm{MPa}$ into a $10 \mathrm{~mm}$ polyether ether ketone (PEEK die) using two titanium plungers. On both sides of the pellet, acetylene black $(\mathrm{AB})$ was added for better contact with the current collectors; once added, the $\mathrm{AB}$ was pressed at $370 \mathrm{MPa}$ using the titanium plungers. The cell configuration was secured into a cell holder and connected to a Solartron 1260 impedance analyzer. Impedance measurements were taken with an applied AC potential of $30 \mathrm{mV}$ over a frequency range of $1 \mathrm{MHz}$ to $1 \mathrm{~Hz}$. Temperature-dependent EIS measurements were also conducted within the glovebox; the sample was heated from $20^{\circ} \mathrm{C}$ to $100{ }^{\circ} \mathrm{C}$ and EIS measurements were recorded at every $20^{\circ} \mathrm{C}$ increment. Measurements were taken only after the 
sample was held at the target temperature for over an hour to allow for equilibration. The heating rate was $2{ }^{\circ} \mathrm{C} / \mathrm{min}$. The activation energy $\left(\mathrm{E}_{\mathrm{a}}\right)$ was calculated from the slope of the resulting Arrhenius plot.

DC polarization was also conducted by the Solartron 1260 impedance analyzer. The cell setup was similar as before; the powder was pressed at $370 \mathrm{MPa}$ into a $10 \mathrm{~mm}$ PEEK die using two titanium plungers and subsequently secured into a cell holder. The applied DC potential was $50 \mathrm{mV}$ and the current response was measured over time.

The model SSSB is composed of $\mathrm{NaCrO}_{2}$ as the positive electrode, Na-Sn (2:1) as the negative electrode, and $\mathrm{Na}_{3} \mathrm{PS}_{4}$ as the electrolyte. The positive electrode is mixed into a composite with a weight ratio of 11:16:1 of $\mathrm{NaCrO}_{2}: \mathrm{Na}_{3} \mathrm{PS}_{4}$ : VGCF. The battery is fabricated through mechanical pressing; $75 \mathrm{mg}$ of $\mathrm{Na}_{3} \mathrm{PS}_{4}$ powder is pressed first at $370 \mathrm{MPa}$, then about $12 \mathrm{mg}$ of the composite $\mathrm{NaCrO}_{2}$ powder is placed on one side of the $\mathrm{Na}_{3} \mathrm{PS}_{4}$ pellet and pressed at the same pressure, and finally on the opposite side of the $\mathrm{Na}_{3} \mathrm{PS}_{4}$, an excess of $\mathrm{Na}-\mathrm{Sn}$ 2:1 alloy $(35 \mathrm{mg})$ is pressed at the same pressure. After securing the cell in a cell holder, the electrical leads were connected to an electrochemical cycler (Landhe). For a rate of $\mathrm{C} / 10$, the current density used was $64 \mu \mathrm{A} \mathrm{cm}^{-2}$.

To incorporate $\mathrm{Na}_{2.25} \mathrm{Y}_{0.25} \mathrm{Zr}_{0.75} \mathrm{Cl}_{6}$ (NYZC0.75) into the model SSSB, NYZC0.75 replaced $\mathrm{Na}_{3} \mathrm{PS}_{4}$ in the composite cathode (still hand-mixed with the same 11:16:1 ratio). For cells cycled at $40^{\circ} \mathrm{C}$, the cell assemblies were placed into a compact box furnace (MTI KSI-1100X) within the Ar-filled glovebox. Current densities ranged from $64 \mu \mathrm{A} \mathrm{cm}^{-2}(\mathrm{C} / 10)$ to $640 \mu \mathrm{A} \mathrm{cm}^{-2}(1 \mathrm{C})$.

After cycling, the cell was disassembled to characterize any material changes.

\section{Characterization $-{ }^{23} \mathrm{Na}$ solid-state Nuclear Magnetic Resonance (NMR)}

All ${ }^{23} \mathrm{Na}$ solid-state NMR experiments were performed on a $3.2 \mathrm{~mm} \mathrm{HX}$ probe on a Bruker Avance III Ultrashield Plus $800 \mathrm{MHz}$ (18.8 T) NMR spectrometer. A $1 \mathrm{M} \mathrm{NaCl}$ aqueous solution, with a reported ${ }^{23} \mathrm{Na}$ chemical shift of $0.04 \mathrm{ppm}^{64}$ was used as reference sample to calibrate the chemical shift scale.

${ }^{23} \mathrm{Na}$ NMR spectra were collected on NYZCx $(\mathrm{x}=0,0.25,0.5,0.75,1)$ compounds with a simple pulse and acquire (zg) sequence and at a magic angle spinning (MAS) rate of $12 \mathrm{kHz}$ as no spectral enhancement was observed at higher spinning speeds. The solid electrolyte samples were packed 
inside $3.2 \mathrm{~mm}$ sapphire rotors in an Ar-filled glovebox to avoid contamination with air or moisture. In addition, a flow of $\mathrm{N}_{2}$ gas was used to spin the samples, providing an inert atmosphere during ${ }^{23} \mathrm{Na} \mathrm{NMR}$ signal acquisition.

Due to the quadrupolar nature of ${ }^{23} \mathrm{Na}$ nuclei $(I=3 / 2)$, the calibrated pulse durations differed for the various ${ }^{23} \mathrm{Na}$ local environments in the samples. Hence, all spectra were obtained using a $30^{\circ}$ radiofrequency $(\mathrm{RF})$ excitation pulse in lieu of a standard $90^{\circ}$ pulse angle to uniformly excite all

${ }^{23} \mathrm{Na}$ spins in the sample and provide internally quantitative ${ }^{23} \mathrm{Na} \mathrm{NMR}$ spectra. The quantitative nature of the so-obtained spectra was confirmed by collecting data using a pulse angle as low as $5^{\circ}$, which showed no change in the relative amounts of each resonance compared to the $30^{\circ}$ pulse data. The power level used for all measurements was $100 \mathrm{~W}(\sim 93 \mathrm{kHz})$ with a $90^{\circ}$ pulse duration of around $2.7 \mu \mathrm{s}$, therefore, a $30^{\circ}$ pulse duration of either 0.9 or $0.95 \mu \mathrm{s}$ was used depending on the optimization of each sample. A 30 s delay was applied before each scan when signal averaging in order to allow full relaxation, where the relaxation times of these samples are $2 \mathrm{~s}$ or below.

\section{Characterization - X-ray Photoelectron Spectroscopy (XPS)}

The powders were adhered onto a small metallic sample stub (Shimadzu) with carbon tape. The metallic stub was secured into a metallic canister and sealed inside the glovebox with clamps.

The metallic canister was placed into a $\mathrm{N}_{2}$ glovebox that is attached to the XPS tool (Kratos Axis Supra), where the sample can be transferred into the analysis chamber without any exposure to ambient air. All measurements were taken using $15 \mathrm{kV} \mathrm{Al} \mathrm{K \alpha}$ radiation at a chamber pressure less than $5 \times 10^{-8}$ torr. For the wide survey scans, a pass energy of $160 \mathrm{eV}$ and a dwell time of $100 \mathrm{~ms}$ was used, but for specific element regions, a pass energy of $20 \mathrm{eV}$, a dwell time of $300 \mathrm{~ms}$, and a step size of $0.05 \mathrm{eV}$ was used. The charge neutralizer was enabled during all the measurements. Data calibration and analysis were conducted using the CasaXPS software, and all region spectra were calibrated using the $\mathrm{C} 1 \mathrm{~s}$ peak.

\section{Acknowledgments}

Funding to support this work was provided by the Energy \& Biosciences Institute through the EBIShell program, contract number PT78832. 
Characterization work was performed in part at the San Diego Nanotechnology Infrastructure (SDNI), a member of the National Nanotechnology Coordinated Infrastructure, which is supported by the National Science Foundation under Grant ECCS-1542148.

XPS was conducted at the University of California, Irvine Materials Research Institute (IMRI) using instrumentation funded in part by the National Science Foundation Major Research Instrumentation Program under Grant CHE-1338173.

Computational work was performed using the Extreme Science and Engineering Discovery Environment (XSEDE), which is supported by National Science Foundation Grant ACI-1053575.

The work done at Brookhaven National Laboratory used beamline 28-ID-1 of the National Synchrotron Light Source II, a US DOE Office of Science User Facility operated for the DOE Office of Science by Brookhaven National Laboratory under contract No. DE-SC0012704.

We acknowledge the support from the USA National Science Foundation under Award Number DMR1608968 for sodium-based chemistries.

We thank Mr. Elias Sebti for useful discussions on the assignment of the NMR data.

We thank Dr. Milan Gembicky at the Crystallography Facility at the University of California, San Diego for assisting on the capillary XRD data collection.

We thank Ms. Hyeseung Chung and Mrs. Baharak Sayahpour for their assistance in conducting experiments.

\section{Author Information}

${ }^{\dagger}$ Erik A. Wu, Swastika Banerjee, and Hanmei Tang contributed equally to the work.

\section{Affiliations}

Department of NanoEngineering, University of California San Diego, La Jolla, CA 92093.

Erik A. Wu, Swastika Banerjee, Hanmei Tang, Jean-Marie Doux, Ji Qi, Zhuoying Zhu, Yixuan Li, Enyue Zhao, Abhik Banerjee, Ying Shirley Meng, and Shyue Ping Ong

Materials Department, University of California Santa Barbara, Santa Barbara, CA, 93106. 
Peter M. Richardson and Raphaële J. Clément

Department of Chemistry, Stony Brook University, Stony Brook, NY 11794.

Antonin Grenier and Karena W. Chapman

Department of Materials Science and Engineering, University of California San Diego, La Jolla, CA 92093.

Grayson Deysher

Department of Chemistry \& Biochemistry, University of California San Diego, La Jolla, CA 92093.

Han Nguyen

Shell International Exploration \& Production Inc., USA

Ryan Stephens

Shell Global Solutions International BV, Netherlands

Guy Verbist

Research Institute for Sustainable Energy (RISE), TCG Centres for Research and Education in Science and Technology (TCG CREST), Sector V, Salt Lake, Kolkata 700091, India.

Abhik Banerjee

Sustainable Power \& Energy Center (SPEC), University of California San Diego, La Jolla, CA 92093.

Ying Shirley Meng and Shyue Ping Ong

\section{Contributions}

E.A.W., S. B., P.M.R., J. Q., and A.B. wrote the manuscript. E.A.W. carried out experimental synthesis and electrochemical measurements and testing. S.B., H.T., Z.Z., and J. Q. conducted the computational work. P. M. R. conducted NMR. A. G. and Y. L. conducted synchrotron XRD measurements, and along with J.-M. D. and E. Z., provided input on analysis. G. D. aided in cell 
construction. H. N. aided with capillary XRD data collection. R. S. and G. V. managed the project and were involved in experimental planning and project discussions. K. W. C. supervised the work of A. G., R. J. C. supervised the work of P. M. R., Y. S. M. and A. B. supervised the work of E. A. W., J.-M. D., Y. L., E. Z., and G. D., and S. P. O. supervised the work of S. B., H. T., J. Q., and Z. Z. All authors helped with data interpretation and analysis.

\section{Corresponding Authors}

* Correspondence to: ongsp@eng.ucsd.edu, shmeng@ucsd.edu, abhik.banerjee@tcgcrest.org, rclement@ucsb.edu

\section{Ethics Declarations}

\section{Competing Interests}

R. S. and G. V. are employees of Shell International Exploration and Production Inc., USA and Shell Global Solutions International BV, Netherlands, respectively.

A patent was filed for this work through the UCSD Office of Innovation and Commercialization.

\section{Data Availability}

The data that support the findings of this study are available from the corresponding authors upon reasonable request. See author contributions for specific data sets.

\section{References}

1. Kamaya, N. et al. A lithium superionic conductor. Nat. Mater. 10, 682-686 (2011).

2. Hayashi, A. et al. A sodium-ion sulfide solid electrolyte with unprecedented conductivity at room temperature. Nat. Commun. 10, 1-6 (2019).

3. Richards, W. D., Miara, L. J., Wang, Y., Kim, J. C. \& Ceder, G. Interface Stability in Solid-State Batteries. Chem. Mater. 28, 266-273 (2016).

4. Kato, Y. et al. High-power all-solid-state batteries using sulfide superionic conductors. Nat. Energy 1, 1-7 (2016). 
5. Banerjee, A. et al. $\mathrm{Na}_{3} \mathrm{SbS}_{4}$ : A Solution Processable Sodium Superionic Conductor for All-Solid-State Sodium-Ion Batteries. Angew. Chem. Int. Ed. 55, 9634-9638 (2016).

6. Wang, Y. et al. Development of solid-state electrolytes for sodium-ion battery-A short review. Nano Mater. Sci. 1, 91-100 (2019).

7. Asano, T. et al. Solid Halide Electrolytes with High Lithium-Ion Conductivity for Application in 4 V Class Bulk-Type All-Solid-State Batteries. Adv. Mater. 30, 1803075 (2018).

8. Li, X. et al. Air-stable $\mathrm{Li}_{3} \mathrm{InCl}_{6}$ electrolyte with high voltage compatibility for all-solidstate batteries. Energy Environ. Sci. 12, 2665-2671 (2019).

9. Liang, J. et al. Site-Occupation-Tuned Superionic $\mathrm{Li}_{x} \mathrm{ScCl}_{3+\times}$ Halide Solid Electrolytes for All-Solid-State Batteries. J. Am. Chem. Soc. 142, 7012-7022 (2020).

10. Wang, S. et al. Lithium Chlorides and Bromides as Promising Solid-State Chemistries for Fast Ion Conductors with Good Electrochemical Stability. Angew. Chem. Int. Ed. 58, 8039-8043 (2019).

11. Wickleder, M. S. \& Meyer, G. Ternäre Halogenide vom Typ A3MX 6 . III [1, 2]. Synthese, Strukturen und Ionenleitfähigkeit der Halogenide $\mathrm{Na}_{3} \mathrm{MX}_{6}(\mathrm{X}=\mathrm{Cl}$, Br). Z. Für Anorg. Allg. Chem. 621, 457-463 (1995).

12. Sun, Y., Suzuki, K., Hori, S., Hirayama, M. \& Kanno, R. Superionic Conductors: $\mathrm{Li}_{10+\delta}\left[\mathrm{Sn}_{\mathrm{y}} \mathrm{Si}_{1-\mathrm{y}}\right]_{1+\delta} \mathrm{P}_{2-\delta} \mathrm{S}_{12}$ with a $\mathrm{Li}_{10} \mathrm{GeP}_{2} \mathrm{~S}_{12}$-type Structure in the $\mathrm{Li}_{3} \mathrm{PS}_{4-}-\mathrm{Li}_{4} \mathrm{SnS}_{4-}$ $\mathrm{Li}_{4} \mathrm{SiS}_{4}$ Quasi-ternary System. Chem. Mater. 29, 5858-5864 (2017).

13. Zhao, W., Yi, J., He, P. \& Zhou, H. Solid-State Electrolytes for Lithium-Ion Batteries: Fundamentals, Challenges and Perspectives. Electrochem. Energy Rev. 2, 574-605 (2019). 
14. Jolley, A. G., Cohn, G., Hitz, G. T. \& Wachsman, E. D. Improving the ionic conductivity of NASICON through aliovalent cation substitution of $\mathrm{Na}_{3} \mathrm{Zr}_{2} \mathrm{Si}_{2} \mathrm{PO}_{12}$. Ionics 21, 30313038 (2015).

15. Ong, S. P. et al. Phase stability, electrochemical stability and ionic conductivity of the $\mathrm{Li}_{10 \pm 1} \mathrm{MP}_{2} \mathrm{X}_{12}(\mathrm{M}=\mathrm{Ge}, \mathrm{Si}, \mathrm{Sn}, \mathrm{Al}$ or $\mathrm{P}$, and $\mathrm{X}=\mathrm{O}, \mathrm{S}$ or $\mathrm{Se})$ family of superionic conductors. Energy Environ. Sci. 6, 148-156 (2012).

16. Zhu, Y. et al. First principles study on electrochemical and chemical stability of solid electrolyte-electrode interfaces in all-solid-state Li-ion batteries. J. Mater. Chem. A 4, 3253-3266 (2016).

17. Yu, C.-Y. et al. $\mathrm{NaCrO}_{2}$ cathode for high-rate sodium-ion batteries. Energy Environ. Sci. 8, 2019-2026 (2015).

18. Tang, H. et al. Probing Solid-Solid Interfacial Reactions in All-Solid-State Sodium-Ion Batteries with First-Principles Calculations. Chem. Mater. 30, 163-173 (2018).

19. Zuo, Y. et al. Performance and Cost Assessment of Machine Learning Interatomic Potentials. J. Phys. Chem. A 124, 731-745 (2020).

20. Shapeev, A. V. Moment Tensor Potentials: A Class of Systematically Improvable Interatomic Potentials. Multiscale Model. Simul. 14, 1153-1173 (2016).

21. Podryabinkin, E. V. \& Shapeev, A. V. Active learning of linearly parametrized interatomic potentials. Comput. Mater. Sci. 140, 171-180 (2017).

22. Gubaev, K., Podryabinkin, E. V., Hart, G. L. W. \& Shapeev, A. V. Accelerating highthroughput searches for new alloys with active learning of interatomic potentials. Comput. Mater. Sci. 156, 148-156 (2019). 
23. Inaguma, Y. et al. High ionic conductivity in lithium lanthanum titanate. Solid State Commun. 86, 689-693 (1993).

24. Liao, W. \& Dronskowski, R. Trisodium yttrium(III) hexachloride. Acta Crystallogr. Sect. E Struct. Rep. Online 60, i72-i73 (2004).

25. Cipriani, C. Ricerche strutturistiche e cristallochimiche sul fluotitanato di sodi, 1955. Period. Mineral. 24, 361-375 (1955).

26. Harris, R. K. \& Nesbitt, G. J. Cross polarization for quadrupolar nuclei-Proton to sodium-23. J. Magn. Reson. 1969 78, 245-256 (1988).

27. Arnold, A. A. et al. Structure of $\mathrm{NaYF}_{4}$ Upconverting Nanoparticles: A Multinuclear Solid-State NMR and DFT Computational Study. J. Phys. Chem. C 117, 25733-25741 (2013).

28. Bessada, C., Rakhmatullin, A., Rollet, A.-L. \& Zanghi, D. High temperature NMR approach of mixtures of rare earth and alkali fluorides: An insight into the local structure. J. Fluor. Chem. 130, 45-52 (2009).

29. Udovic, T. J. et al. Exceptional Superionic Conductivity in Disordered Sodium Decahydro-closo-decaborate. Adv. Mater. 26, 7622-7626 (2014).

30. Verdal, N. et al. Anion Reorientations in the Superionic Conducting Phase of $\mathrm{Na}_{2} \mathrm{~B}_{12} \mathrm{H}_{12}$. J. Phys. Chem. C 118, 17483-17489 (2014).

31. Martelli, P. et al. Rotational Motion in $\mathrm{LiBH}_{4} / \mathrm{LiI}$ Solid Solutions. J. Phys. Chem. A 115, 5329-5334 (2011).

32. Zhang, Z. et al. Targeting Superionic Conductivity by Turning on Anion Rotation at Room Temperature in Fast Ion Conductors. Matter 2, 1667-1684 (2020). 
33. Banerjee, S., Zhang, X. \& Wang, L.-W. Motif-Based Design of an Oxysulfide Class of Lithium Superionic Conductors: Toward Improved Stability and Record-High Li-Ion Conductivity. Chem. Mater. 31, 7265-7276 (2019).

34. Duchêne, L. et al. Crystallization of closo-borate electrolytes from solution enabling infiltration into slurry-casted porous electrodes for all-solid-state batteries. Energy Storage Mater. 26, 543-549 (2020).

35. Duchêne, L. et al. A stable $3 \mathrm{~V}$ all-solid-state sodium-ion battery based on a closo-borate electrolyte. Energy Environ. Sci. 10, 2609-2615 (2017).

36. Hayashi, A., Noi, K., Tanibata, N., Nagao, M. \& Tatsumisago, M. High sodium ion conductivity of glass-ceramic electrolytes with cubic $\mathrm{Na}_{3} \mathrm{PS}_{4}$. J. Power Sources $\mathbf{2 5 8}$, $420-423$ (2014).

37. Ando, T., Sakuda, A., Tatsumisago, M. \& Hayashi, A. All-solid-state sodium-sulfur battery showing full capacity with activated carbon MSP20-sulfur-Na3 $\mathrm{SbS}_{4}$ composite. Electrochem. Commun. 116, 106741 (2020).

38. Wan, H. et al. Core-Shell $\mathrm{Fe}_{1-\mathrm{x}} \mathrm{S} @ \mathrm{Na}_{2.9} \mathrm{PS}_{3.95} \mathrm{Se}_{0.05}$ Nanorods for Room Temperature AllSolid-State Sodium Batteries with High Energy Density. ACS Nano 12, 2809-2817 (2018).

39. Zhang, S. et al. Gradiently Sodiated Alucone as an Interfacial Stabilizing Strategy for Solid-State Na Metal Batteries. Adv. Funct. Mater. 30, 2001118 (2020).

40. Yue, J. et al. High-Performance All-Inorganic Solid-State Sodium-Sulfur Battery. ACS Nano 11, 4885-4891 (2017). 
41. Rao, R. P., Zhang, X., Phuah, K. C. \& Adams, S. Mechanochemical synthesis of fast sodium ion conductor $\mathrm{Na}_{11} \mathrm{Sn}_{2} \mathrm{PSe}_{12}$ enables first sodium-selenium all-solid-state battery. J. Mater. Chem. A 7, 20790-20798 (2019).

42. Wan, H. et al. Nanoscaled $\mathrm{Na}_{3} \mathrm{PS}_{4}$ Solid Electrolyte for All-Solid-State $\mathrm{FeS}_{2} / \mathrm{Na}$ Batteries with Ultrahigh Initial Coulombic Efficiency of 95\% and Excellent Cyclic Performances. ACS Appl. Mater. Interfaces 10, 12300-12304 (2018).

43. Heo, J. W., Banerjee, A., Park, K. H., Jung, Y. S. \& Hong, S.-T. New Na-Ion Solid Electrolytes $\mathrm{Na}_{4-\mathrm{x}} \mathrm{Sn}_{1-\mathrm{x}} \mathrm{Sb}_{\mathrm{x}} \mathrm{S} 4(0.02 \leq \mathrm{x} \leq 0.33)$ for All-Solid-State Na-Ion Batteries. Adv. Energy Mater. 8, 1702716 (2018).

44. Murgia, F., Brighi, M. \& Černý, R. Room-temperature-operating Na solid-state battery with complex hydride as electrolyte. Electrochem. Commun. 106, 106534 (2019).

45. Santhosha, A. L., Medenbach, L., Palaniselvam, T. \& Adelhelm, P. Sodium-Storage Behavior of Exfoliated $\mathrm{MoS}_{2}$ as an Electrode Material for Solid-State Batteries with $\mathrm{Na}_{3} \mathrm{PS}_{4}$ as the Solid Electrolyte. J. Phys. Chem. C 124, 10298-10305 (2020).

46. Zhang, D. et al. Synthesis of cubic $\mathrm{Na}_{3} \mathrm{SbS}_{4}$ solid electrolyte with enhanced ion transport for all-solid-state sodium-ion batteries. Electrochimica Acta 259, 100-109 (2018).

47. Chi, X. et al. Tailored Organic Electrode Material Compatible with Sulfide Electrolyte for Stable All-Solid-State Sodium Batteries. Angew. Chem. Int. Ed. 57, 2630-2634 (2018).

48. Hao, F. et al. Taming Active Material-Solid Electrolyte Interfaces with Organic Cathode for All-Solid-State Batteries. Joule 3, 1349-1359 (2019).

49. Moon, C. K. et al. Vacancy-Driven Na+ Superionic Conduction in New Ca-Doped $\mathrm{Na}_{3} \mathrm{PS}_{4}$ for All-Solid-State Na-Ion Batteries. ACS Energy Lett. 3, 2504-2512 (2018). 
50. Fan, X. et al. High-Performance All-Solid-State Na-S Battery Enabled by CastingAnnealing Technology. ACS Nano 12, 3360-3368 (2018).

51. Tan, D. H. S. et al. Elucidating Reversible Electrochemical Redox of $\mathrm{Li}_{6} \mathrm{PS}_{5} \mathrm{Cl}$ Solid Electrolyte. ACS Energy Lett. 4, 2418-2427 (2019).

52. Tian, Y. et al. Compatibility issues between electrodes and electrolytes in solid-state batteries. Energy Environ. Sci. 10, 1150-1166 (2017).

53. Kresse, G. \& Furthmüller, J. Efficient iterative schemes for ab initio total-energy calculations using a plane-wave basis set. Phys. Rev. B 54, 11169-11186 (1996).

54. Blöchl, P. E. Projector augmented-wave method. Phys. Rev. B 50, 17953-17979 (1994).

55. Perdew, J. P., Burke, K. \& Ernzerhof, M. Generalized Gradient Approximation Made Simple. Phys. Rev. Lett. 77, 3865-3868 (1996).

56. Ong, S. P. et al. Python Materials Genomics (pymatgen): A robust, open-source python library for materials analysis. Comput. Mater. Sci. 68, 314-319 (2013).

57. Deng, Z., Zhu, Z., Chu, I.-H. \& Ong, S. P. Data-Driven First-Principles Methods for the Study and Design of Alkali Superionic Conductors. Chem. Mater. 29, 281-288 (2017).

58. Jain, A. et al. Commentary: The Materials Project: A materials genome approach to accelerating materials innovation. APL Mater. 1, 011002 (2013).

59. Ong, S. P. et al. The Materials Application Programming Interface (API): A simple, flexible and efficient API for materials data based on REpresentational State Transfer (REST) principles. Comput. Mater. Sci. 97, 209-215 (2015).

60. Bergerhoff, G., Hundt, R., Sievers, R. \& Brown, I. D. The inorganic crystal structure data base. J. Chem. Inf. Comput. Sci. 23, 66-69 (1983). 
61. Ong, S. P., Wang, L., Kang, B. \& Ceder, G. Li-Fe-P- $\mathrm{O}_{2}$ Phase Diagram from First Principles Calculations. Chem. Mater. 20, 1798-1807 (2008).

62. Willems, T. F., Rycroft, C. H., Kazi, M., Meza, J. C. \& Haranczyk, M. Algorithms and tools for high-throughput geometry-based analysis of crystalline porous materials. Microporous Mesoporous Mater. 149, 134-141 (2012).

63. Plimpton, S. Fast parallel algorithms for short-range molecular dynamics. https://www.osti.gov/biblio/10176421 (1993) doi:10.2172/10176421.

64. Makulski, W. Multinuclear Magnetic Resonance Study of Sodium Salts in Water Solutions. Magnetochemistry 5, 68 (2019). 